\title{
ADAPTAÇÃO DA LISTA DE VERIFICAÇÃO DE CIRURGIA SEGURA PARA O CONTEXTO DA COVID-19
}

Thais da Costa Oliveira ${ }^{1}$

Paula Alencar Gonçalves ${ }^{1}$

Thatiane Albuquerque da Costa Lima https://orcid.org/0000-0003-2802-8454

https://orcid.org/0000-0001-6662-6880

https://orcid.org/0000-0001-9497-5615

Objetivo: Relatar a experiência acerca da adaptação da lista de verificação de cirurgia segura para procedimentos de pacientes em isolamento respiratório no contexto da Covid-19. Método: A experiência fo i desenvolvida por um grupo de enfermeiras assistenciais de um hospital universitário, utilizando-se os pressupostos do checklist de cirurgia segura da Organização Mundial de Saúde e as recomendações das entidades científicas nacionais e internacionais para adaptar a lista de verificação de segurança cirúrgica para os procedimentos de pacientes em isolamento respiratório no contexto da Covid-19. Resultados: A lista de verificação adaptada contemplou elementos organizacionais pré e pós-procedimento para orientar a supervisão do enfermeiro de centro cirúrgico, otimizando recursos físicos e materiais, uso de equipamentos de proteção individual e minimizando o risco de transmissão intra-hospitalar da Covid-19. Conclusão: A experiência contribuiu para relacionar a segurança cirúrgica no contexto pandêmico da Covid-19, tendo em vista a manutenção de procedimentos cirúrgicos não adiáveis, retomada dos cronogramas cirúrgicos eletivos e redução dos incidentes de segurança neste público.

Descritores: Lista de verificação; Centros Cirúrgicos; Segurança do paciente; Infecções por Coronavírus.

\section{ADAPTATION OF THE SAFE SURGERY CHECKLIST TO THE CONTEXT OF COVID-19}

Objectivos: Report an experience report about the adaptation of the safe surgery checklist for procedures of patients in respiratory isolation in the context of COVID-19. Method: The experience was developed by a group of nurse assistants from a university hospital, using the assumptions of the World Health Organization's safe surgery checklist and the recommendations of national and international scientific entities to adapt the surgical safety checklist for patients procedures in respiratory isolation in the context of COVID-19. Results: The adapted checklist included pre- and post-procedure organizational elements to guide the supervision of the operating room nurse, optimizing physical and material resources, use of personal protective equipment and minimizing the risk of intra-hospital transmission of COVID-19. Conclusion: The experience contributed to relate surgical safety in the pandemic context of COVID-19, with a view to maintaining non-postponing surgical procedures, resuming elective surgical schedules and reducing safety incidents in this public.

Descriptors: Checklist; Surgical Centers; Patient safety; Coronavirus infections.

\section{ADAPTACIÓN DE LA LISTA DE VERIFICACIÓN DE CIRURGÍA SEGURAAL CONTEXTO DE COVID-19}

Objetivos: Informar la experiencia sobre la adaptación de la lista de verificación de cirugía segura para procedimientos de pacientes en aislamiento respiratorio en el contexto de COVID-19. Metodo: La experiencia fue desarrollada por un grupo de asistentes de enfermería de un hospital universitario, utilizando los supuestos de la lista de verificación de cirugía segura de la Organización Mundial de la Salud y las recomendaciones de entidades científicas nacionales e internacionales para adaptar la lista de verificación de seguridad quirúrgica para los pacientes. procedimientos para pacientes en aislamiento respiratorio en el contexto de COVID-19. Resultados: La lista de verificación adaptada incluía elementos organizativos previos y posteriores al procedimiento para guiar la supervisión de la enfermera del quirófano, optimizando los recursos físicos y materiales, el uso de equipos de protección personal y minimizando el riesgo de transmisión intrahospitalaria de COVID-19. Conclusión: La experiencia contribuyó a relacionar la seguridad quirúrgica en el contexto pandémico de COVID-19, con miras a mantener procedimientos quirúrgicos no pospuestos, reanudar los horarios quirúrgicos electivos y reducir los incidentes de seguridad en este público. Descriptores: Lista de verificación; Centros quirúrgicos; Seguridad del paciente; Infecciones por coronavirus.

${ }^{1}$ Hospital Universitário Professor Alberto Antunes (HUPAA), Maceió, AL, Brasil Autor Correspondente: Thais da Costa Oliveira E-mail - enfthais.costa@outlook.com

Recebido: 11/6/20 Aceito: $23 / 6 / 20$ 


\section{INTRODUÇÃO}

O SARS-CoV-2 é um vírus da família coronavírus responsável por doenças respiratórias em diferentes animais, detectado pela primeira vez em um surto na cidade de Wuhan - China em dezembro de 20191. A partir da transmissão pessoa-pessoa do vírus a gravidade da situação chegou a nível internacional com a decretação do estado de pandemia pela infecção por coronavírus (Covid-19)2. A pandemia da Covid-19 provocou inúmeras consequências a nivel global, na saúde, economia, relações sociais e meio ambiente, levando ao colapso de grandes sistemas de saúde pela sua rápida disseminação e dificuldade de controle ${ }^{3}$.

A Covid-19 mudou o cenário epidemiológico mundial, e exige da sociedade medidas urgentes de adaptação e minimização dos danos provocados pela pandemia ${ }^{3}$. Nos centros cirúrgicos, a possibilidade de contágio paciente-paciente e paciente-profissional é elevada, dada a grande manipulação de vias aéreas, procedimentos anestésicos e dificuldades de comunicação entre os membros da equipe ${ }^{4}$

A prática cirúrgica foi afetada diretamente, pela suspensão de procedimentos eletivos e a priorização de cirurgias de urgência e emergência, objetivando reserva de leitos para pacientes com infecção respiratória, principalmente em unidades de terapia intensiva ${ }^{5}$. Assim, o planejamento para a manutenção e retomada dos procedimentos cirúrgicos, de forma geral, deve ser baseado em novos protocolos e práticas para a prevenção e controle da transmissão do novo coronavírus dentro dos serviços de saúde. De forma gradativa os serviços terão de reiniciar seus cronogramas cirúrgicos e muitos procedimentos irão ocorrer em meio ao centro da infecção ${ }^{5}$.

Este cenário de risco exige interdependência entre o cuidado cirúrgico, prevenção e controle de infecções, notadamente a Covid-19 e segurança do paciente, contribuindo para a interseção de áreas sensíveis à qualidade dos serviços de saúde ${ }^{6.7}$. O medo da contaminação, o impacto das condições de trabalho e uso rigoroso de equipamentos de proteção individual serão ainda mais presentes e provocarão grandes mudanças na assistência à saúde $e^{5,6,7}$.

A vulnerabilidade do paciente cirúrgico a erros no cuidado, principalmente durante a pandemia da Covid-19 fez surgir a discussão sobre a adaptação da lista de verificação de cirurgia segura a essa nova realidade a fim de agregar as particularidades inerentes a procedimentos em pessoas sob isolamento respiratório e promover uma assistência segura para pacientes e profissionais. Este estudo traz como objetivo relatar a experiência de enfermeiras na adaptação da lista de verificação de cirurgia segura para os pacientes em isolamento respiratório, principalmente no contexto da Covid-19.

\section{MÉTODO}

Este estudo traz um relato de experiência de enfermeiras assistenciais do Centro Obstétrico de uma maternidade de um hospital público de ensino, localizado no nordeste do Brasil, ocorrido entre abril e maio de 2020. Participaram da experiência três enfermeiras assistenciais do Centro Obstétrico da maternidade.

A elaboração e avaliação do checklist utilizou como referência a lista de verificação do Programa Cirurgias Seguras Salvam Vidas ${ }^{8}$, contemplando as etapas já previstas de sign in (antes da indução anestésica), time out (pausa cirúrgica) e sign out (antes da saída da sala). Além disso, utilizou-se os princípios do programa quanto à simplicidade, aplicabilidade e possibilidade de mensuração do instrumento. Os tópicos generalistas e relevantes para todos os tipos de procedimentos cirúrgicos foram mantidos.

A adaptação do checklist foi realizada em duas etapas: na etapa de planejamento, a equipe utilizou a técnica de brainstorming (tempestade de ideias) para identificar os pontos principais a serem acrescentados no checklist da Organização Mundial de Saúde (OMS), identificando e listando os itens da versão preliminar do instrumento.

$\mathrm{Na}$ segunda etapa, foi realizada uma revisão narrativa de literatura para fundamentar e atualizar os tópicos inseridos e adaptados para o instrumento tradicional. Para tanto, foram consultadas as notas técnicas mais recentes da Agência Nacional de Vigilância Sanitária (ANVISA) e a Biblioteca Virtual em Saúde (BVS), a qual direciona para as principais bases de dados nacionais e internacionais. Utilizou-se a seguinte estratégia de busca: "Covid-19" AND "segurança do paciente" AND "centros cirúrgicos" OR "cirurgias".

\section{OBJETIVOS DA EXPERIÊNCIA}

O objetivo da experiência foi relatar o desenvolvimento e uso de checklist adaptado de cirurgia segura como instrumento de supervisão para procedimentos cirúrgicos em pacientes em isolamento respiratório, sobretudo no contexto da Covid-19.

\section{DESCRIÇÃO DA EXPERIÊNCIA}

A experiência iniciou-se com a identificação da necessidade de aliar a manutenção dos procedimentos cirúrgicos não adiáveis (principalmente cesáreas), as precauções para controle de infecção, organização dos serviços e profissionais para evitar contaminação. As enfermeiras assistenciais utilizaram a lista de verificação da OMS para fundamentar a adaptação para um checklist próprio que contemplasse tanto as questões de segurança já propostas por ela, quanto as novas recomendações de prevenção e controle da Covid-19, 
divulgadas pela literatura nacional e internacional.

Na etapa de revisão de literatura, ao se utilizar a estratégia de busca proposta, encontrou-se 56 artigos, destes apenas quatro continham em seus resultados aspectos que puderam reafirmar e complementar as orientações dos órgãos de saúde nacionais e internacionais e assim contribuir para a adaptação da lista de verificação de cirurgia segu- ra, como pode ser observado no quadro l. Ressalta-se que todos esses estudos foram do tipo revisão de literatura, sendo dois indexados na base de dados Índice Bibliográfico Español en Ciencias de la Salud (IBECS), um na Medical Literature Análise e Retrieual System on-line (MEDLINE) e outro na Literatura Latino-Americana e do Caribe Ciências da Saúde (LILACS).

Quadro 1 - Artigos selecionados através da Biblioteca Virtual em Saúde para subsidiar a adaptação da lista de verificação de cirurgia segura para o contexto da Covid 2019.

\begin{tabular}{|c|c|c|c|c|}
\hline Artigo & Autores & $\begin{array}{l}\text { Periódico, Ano } \\
\text { de publicação }\end{array}$ & $\begin{array}{c}\text { Base de } \\
\text { dados }\end{array}$ & $\begin{array}{l}\text { Contribuições para a adaptação da lista de } \\
\text { verificação }\end{array}$ \\
\hline $\begin{array}{l}\text { Manejo quirúrgico de } \\
\text { pacientes con infec- } \\
\text { ción por Covid-19. } \\
\text { Recomendaciones de } \\
\text { la Asociación Españo- } \\
\text { la de Cirujanos / Sur- } \\
\text { gical Management of } \\
\text { Patients With Covid-19 } \\
\text { Infection. Recommen- } \\
\text { dations of the Spanish } \\
\text { Association of Sur- } \\
\text { geons }{ }^{9}\end{array}$ & $\begin{array}{l}\text { Balibrea JM, Badia } \\
\text { JM, Pérez IR, An- } \\
\text { tona EM, Peña EA, } \\
\text { Botella SG, et al. }\end{array}$ & $\begin{array}{l}\text { Cir. Esp. (Ed. } \\
\text { impr.) } 2020\end{array}$ & IBECS & $\begin{array}{l}\text { - Designar uma sala cirúrgica para pacientes } \\
\text { Covid 19; } \\
\text { - Limitar número de pessoas em sala cirúr- } \\
\text { gica; } \\
\text { - Revisão da história clínica e avaliação de } \\
\text { exames complementares; } \\
\text { - Revisão do caso com a equipe médica; } \\
\text { - Paramentação completa para precauções } \\
\text { de contato e aerossol antes da entrada do } \\
\text { paciente; } \\
\text { - Realização de anamnese concisa e clara } \\
\text { devido à paramentação e os ruidos do am- } \\
\text { biente; } \\
\text { - Paramentação da equipe no pós-operató- } \\
\text { rio para transporte do paciente. } \\
\text { - Descarte imediato dos materiais utilizados. }\end{array}$ \\
\hline $\begin{array}{l}\text { Surgical Infection So- } \\
\text { ciety Guidance for Op- } \\
\text { erative and Peri-Op- } \\
\text { erative Care of Adult } \\
\text { Patients Infected by the } \\
\text { Severe Acute Respira- } \\
\text { tory Syndrome Corona- } \\
\text { virus-2 (SARS-CoV-2) }\end{array}$ & $\begin{array}{l}\text { Heffernan DS, } \\
\text { Evans HL, Huston } \\
\text { JM, Claridge JA, } \\
\text { Blake DP, May AK, } \\
\text { et al. }\end{array}$ & $\begin{array}{l}\text { Surg Infect } \\
\text { (Larchmt), } 2020\end{array}$ & $\begin{array}{l}\text { MEDLI- } \\
\text { NE }\end{array}$ & $\begin{array}{l}\text { - Limitar número de pessoas em sala cirúr- } \\
\text { gica; } \\
\text { - Manutenção do uso dos EPI's durante todo } \\
\text { o procedimento e transporte do paciente; } \\
\text { - Designar uma sala cirúrgica para pacientes } \\
\text { Covid 19; } \\
\text { - Paramentação de toda a equipe envolvida } \\
\text { no procedimento antes da chegada do pa- } \\
\text { ciente; } \\
\text { - Pacientes extubados devem fazer recu- } \\
\text { peração pós-anestésica em sala, se estiver } \\
\text { entubado providenciar ventilador de trans- } \\
\text { porte. }\end{array}$ \\
\hline $\begin{array}{l}\text { Recomendaciones para } \\
\text { la ejecución de aneste- } \\
\text { sia regional no obstétri- } \\
\text { ca en perioperatorio de } \\
\text { pacientes Covid-1911 }\end{array}$ & $\begin{array}{l}\text { Aliste J, Altermatt } \\
\text { F, Atton R, Bravo } \\
\text { D, Layera S, Miran- } \\
\text { da P, et al. }\end{array}$ & $\begin{array}{l}\text { Rev. chil. anest. } \\
2020\end{array}$ & LILACS & $\begin{array}{l}\text { - Manter paciente em uso de anestesia regio- } \\
\text { nal com máscara cirúrgica durante a cirurgia } \\
\text { e fazer recuperação pós-anestésica na sala; } \\
\text { - Equipe paramentada para contato e aeros- } \\
\text { sóis para possível necessidade de intubação. }\end{array}$ \\
\hline $\begin{array}{l}\text { Recomendaciones } \\
\text { prácticas para el ma- } \\
\text { nejo perioperatorio del } \\
\text { paciente con sospecha } \\
\text { o infección grave por } \\
\text { coronavirus SARS- } \\
\text {-CoV-2 }\end{array}$ & $\begin{array}{l}\text { Montero Fei- } \\
\text { joo A, Maseda } \\
\text { E, Adalia Barto- } \\
\text { lomé R, Aguilar } \\
\text { G, González de } \\
\text { Castro R, Gómez- } \\
\text {-Herrerasu I, et al. }\end{array}$ & $\begin{array}{l}\text { Rev. esp. anes- } \\
\text { tesiol. reanim/ } \\
2020\end{array}$ & IBECS & $\begin{array}{l}\text { - Paramentação completa para precauções de } \\
\text { contato e aerossolantes da entrada do paciente; } \\
\text { - Manter paciente em uso de máscara cirúrgica; } \\
\text { - Manter equipe mínima em sala cirúrgica; } \\
\text { - Utilizar filtros bacterianos em material respirató- } \\
\text { rio; } \\
\text { - Realizar recuperação pós-anestésica em sala. }\end{array}$ \\
\hline
\end{tabular}


No brainstorming, as enfermeiras observaram a dificuldade em se implementar as recomendações dos órgãos governamentais ${ }^{6,7.13}$, bem como da literatura consultada sobre os fluxos assistenciais e uso racional de EPI na rotina do serviço, e passaram a discutir como estas recomendações se aplicariam no ambiente cirúrgico tradicional. Desta etapa, surgiram ideias de adaptação dos tópicos do checklist, principalmente na primeira etapa (antes da indução anestésica), com enfoque para a comunicação entre as equipes e setores, além do pre- paro do ambiente para a realização do procedimento.

Após a rodada de brainstorming e discussões iniciais, foi elaborada uma lista com as principais inclusões necessárias ao contexto assistencial cirúrgico na Covid-19, optando-se por adicionar as etapas "pré-procedimento" e "pós-procedimento", tendo em vista a relevância da organização da assistência para a prevenção da contaminação entre os sujeitos do cuidado. A seguir, o quadro 2 evidencia os itens adicionados, conforme cada etapa do checklist de cirurgia segura.

Quadro 2 - Itens específicos para o contexto da Covid-19 em ambientes cirúrgicos, Maceió, Alagoas, Brasil, 2020.

Etapa Itens

Pré-procedimento No Centro Cirúrgico:

-A sala cirúrgica tem o mínimo possivel de materiais e mobiliários e mesa cirúrgica está distante dois metros do berço aquecido?

-Medicamentos acondicionados em sacos plásticos e os psicobox fora da sala cirúrgica?

-Equipamentos e válvulas estão envoltos em sacos plásticos?

-Equipe é mínima possível e está paramentada para precaução de contato e aerossol?

-Filtros bacterianos e virais instalados nos circuitos ventilatórios e saídas expiratórias do apare-

Antes da indução anes-

tésica

lho de anestesia?

-Pinça de clampeamento do tubo endotraqueal disponível?

-Sistema fechado de aspiração traqueal disponivel?

-Ar condicionado desligado durante manuseio das vias aéreas?

Antes da incisão cirúrgica

-Bisturi elétrico, se possivel, desconectado?

-Setor de origem comunicado?

Antes do paciente sair da sala cirúrgica

-Ventilador de transporte com filtros bacterianos e virais disponível?

-Equipe de transporte paramentada para precaução de contato e aerossol?

Pós-procedimento 
A lista de verificação desenvolvida está sendo utilizada como um instrumento prático do grupo de enfermeiras assistenciais para a supervisão e organização dos procedimentos em Covid-19, carecendo de validação de conteúdo para uso individual nos pacientes, sendo esta a próxima etapa do grupo do estudo. A ferramenta tem proporcionado sistematização das condutas recomendadas e padronização das estratégias de prevenção da transmissão intra-hospitalar do Sars-Cov-2. O quadro 3, abaixo, demonstra a lista de verificação adaptada.

Quadro 3 - Lista de verificação utilizada para cirurgia segura em pacientes sob isolamento respiratório no contexto da Covid-19, Maceió, Alagoas, Brasil, 2020.






\begin{tabular}{|c|c|c|}
\hline Antes da incisão cirúrgica & TIME OUT & $\begin{array}{l}\text {-Apresentação oral, nome e função de todos os profissionais } \\
\text {-Cirurgiões, anestesistas e equipe de enfermagem confirmam: Identificação do cliente Sitio cirúrgico Pro- } \\
\text { cedimento a ser realizado } \\
\text {-Uso de antibiótico profilático } 60 \text { minutos antes? } \\
\text {-Exames de imagem estão disponiveis? } \\
\text { - Revisão do cirurgião: Passos críticos/ Duração estimada /Possiveis perdas sanguineas } \\
\text {-Revisão do anestesista } \\
\text {-Fixação das etiquetas de esterilização no prontuário } \\
\text {-Bisturi elétrico, se possivel, desconectado? }\end{array}$ \\
\hline $\begin{array}{l}\text { Antes do paciente sair da sala } \\
\text { cirúrgica }\end{array}$ & $\begin{array}{l}\text { S I G N } \\
\text { OUT }\end{array}$ & $\begin{array}{l}\text {-Setor de origem comunicado? } \\
\text {-Ventilador de transporte com filtros bacterianos e virais disponivel? } \\
\text {-Equipe de transporte paramentada para precaução de contato e aerossol? } \\
\text { - A contagem de compressas, agulhas e instrumentais está correta? } \\
\text { - Peças anatômicas/culturas e identificadas adequadamente e requisição preenchida? } \\
\text { - Houve algum problema com equipamentos que deve ser resolvido? }\end{array}$ \\
\hline Pós-procedimento & & $\begin{array}{l}\text {-Todos os insumos excedentes com embalagem de papel desprezados? } \\
\text {-Debriefing }\end{array}$ \\
\hline
\end{tabular}

\section{PRINCIPAIS RESULTADOS ALCANÇADOS}

A adaptação da lista de verificação trouxe um instrumento prático a ser utilizado, a priori, como ferramenta de supervisão do enfermeiro na organização do atendimento em procedimentos cirúrgicos de pacientes COVID-19, proporcionando melhor gerenciamento do cuidado e uso de recursos físicos/humanos.

\section{Limitações Do Estudo}

As limitações do estudo se referem ao próprio tipo de estudo, como relato de experiência e a ausência da validação do instrumento para uso por pacientes. A proposta das autoras é de realizar a validação de conteúdo através de avaliação e parecer de especialistas a fim de se verificar se o instrumento atende aos princípios do programa de cirurgia segura.

\section{Contribuições para A Prática}

A experiência contribuirá para somar esforços na qualificação do cuidado durante a pandemia da COVID-19 nos ambientes cirúrgicos e no apoio das equipes de Enfermagem para a organização do cuidado cirúrgico, com diminuição do risco de danos aos pacientes, melhora da comunicação da equipe cirúrgica, otimização de recursos materiais e profissionais.

\section{CONSIDERAÇÕES FINAIS}

A pandemia da COVID-19 trouxe muitos desafios para os serviços da saúde, e as equipes de Centro Cirúrgico passaram a unir a demanda assistencial cirúrgica, visando qualidade da assistência e prevenção de eventos adversos, a precauções de infecções respiratórias, em pacientes suspeitos ou confirmados COVID-19. Esta preocupação tornou-se emergente, mas não é recente, já que os serviços já recebiam público com situações de isolamento, notadamente não em um fluxo tão elevado quanto numa pandemia.

A adaptação da lista de verificação de cirurgia segura contribuiu para nortear a assistência e como um instrumento prático de supervisão para a equipe de enfermeiras organizarem o cuidado evitando desperdício de insumos, otimização da equipe e prevenção de contaminação.

O instrumento adaptado poderá ser validado para uso individual e será um relevante meio de promoção da segurança do paciente na assistência cirúrgica durante e após a pandemia da COVID-19, considerando a necessidade de se manter o fluxo dos procedimentos cirúrgico e a assistência segura.

Contribuições dos Autores: Thais da Costa Oliveira: a) concepção e/ou desenho do estudo; b) coleta, análise e interpretação dos dados; c) redação e/ou revisão crítica do manuscrito; d) aprovação da versão final a ser publicada. Paula Alencar Gonçalves: b) coleta, análise e interpretação dos dados; c) redação e/ou revisão crítica do manuscrito; d) aprovação da versão final a ser publicada. Thatiane Albuquerque da Costa Lima: b) coleta, análise e interpretação dos dados; c) redação e/ou revisão crítica do manuscrito; d) aprovação da versão final a ser publicada. 


\section{REFERÊNCIAS}

1. World Health Organization. Director-General's remarks at the media briefing on 2019-nCoV on 11 February 2020 [cited 2020 Jun 01]. Available from: https://www.who.int/dg/speeches/ detail/who-director-general-s-remarks-at-the-media-briefingon-2019-ncov-on-ll-february-2020.

2. Centers for Disease Control and Prevention. 2019 Novel coronavirus, Wuhan, China. Information for Healthcare Professionals. Washington, 2020 [cited 2020 Jun Ol]. Available from: https://www.cdc.gov/coronavirus/2019-nCoV/hcp/index. html.

3. Santos CF. Reflections about the impact of the SARSCOV-2/COVID-19 pandemic on mental health. São Paulo: Braz J Psychiatry; 2020 [cited 2020 Jun 01]. Available from: http:// dx.doi.org/10.1590/1516-4446-2020-0981.

4. Aminian A, Safari S, Razeghian-Jahromi A, Ghorbani M, Delaney CP. COVID-19 Outbreak and Surgical Practice: Unexpected Fatality in Perioperative Period. Washington: Ann Surg; 2020 [cited 2020 Jun 02]. Available from: https://pubmed.ncbi.nlm.nih. gov/32221117/

5. Forrester JD, Nassar Ak, Maggio PM, Hawn MT. Precautions for operating room team members during COVID-19 pandemic. Washington: Journal of American College of Surgeons; 2020 [cited 2020 Jun 02]. Available from: https://www.journalacs.org/ article/S1072-7515(20)30303-3/fulltext.

6.Agência Nacional de Vigilância Sanitária (ANVISA). Nota Técnica GVIMS/GGTES/ANVISA № 06/2020: Orientações para a prevenção e o controle das infecções pelo novo coronavirus (SARS-CoV-2) em procedimentos cirúrgicos. Brasilia: ANVISA; 2020 [cited 2020 Jun 02]. Available from: http://portal.anvisa.gov.br/documents/33852/271858/ NOTA+T\%C3\%89CNICA+N\%C2\%BA+05-2020+GVIMS-GGTESANVISA+-+ORIENTA\%C3\%87\%C3\%95ES+PARA+A+PREVEN\%C $3 \% 87 \% \mathrm{C} 3 \% 83 \mathrm{O}+\mathrm{E}+\mathrm{O}+\mathrm{CONTROLE}+\mathrm{DE}+\mathrm{INFEC} \% \mathrm{C} 3 \% 87 \% \mathrm{C} 3 \% 9$ 5ES+PELO+NOVO+CORONAV\%C3\%8DRUS+EM+INSTITUI\%C3 $\% 87 \%$ C3\%95ES+DE+LONGA+PERMAN\%C3\%8ANCIA+PARA+ID OSOS\%28ILPI\%29/8dcf5820-fe26-49dd-adf9-lcee4e6d3096.

7. Associação Brasileira de Enfermeiros de Centro Cirúrgico, Centro de Material e Esterilização e Recuperação Anestésica (SOBECC). Recomendaçõesrelacionadasaofluxodeatendimento para pacientes com suspeita ou infecção confirmada pelo covid-19 em procedimentos cirúrgicos ou endoscópicos. Brasilia:
SOBECC; 2020 [cited Jun 03], 2 ed. Available from: http:// sobecc.org.br/arquivos/RECOMENDACOES_COVID_-19_ SOBECC_MARCO_20201.pdf.

8. Organização Mundial da Saúde (OMS). Segundo desafio global para a segurança do paciente: Cirurgias seguras salvam vidas (orientações para cirurgia segura da OMS). Tradução de Marcela Sánchez Nilo e Irma Angélica Durán. Rio de Janeiro: Organização Pan-Americana da Saúde; 2009 [cited Jun 04] Available from: https://bvsms.saude.gov.br/bvs/publicacoes/ seguranca_paciente_cirurgias_seguras_salvam_vidas.pdf.

9. Balibrea JM, Badia JM, Pérez IR, Antona EM, Peña EA, Botella SG, et al. Manejo quirúrgico de pacientes con infección por COVID-19. Recomendaciones de la Asociación Española de Cirujanos. Madrid: Cir. Esp.; 2020 [cited 2020 Jun 04], 98 (5) p.251-259. DOI: 10.1016/j.ciresp.2020.03.001

10. Heffernan DS, Evans HL, Huston JM, Claridge JA, Blake DP. May AK, et al. Surgical Infection Society Guidance for Operative and Peri-Operative Care of Adult Patients Infected by the Severe Acute Respiratory Syndrome Coronavirus-2 (SARS-CoV-2). New York: Surgical Infections; 2020 [cited 2020 Jun 03]. Doi:https://doi.org/10.1089/sur.2020.101.

11. Aliste J, Altermatt F, Atton R, Bravo D, Layera S, Miranda P, et al. Recomendaciones para la ejecución de anestesia regional no obstétrica en perioperatorio de pacientes COVID-19. Madrid: Anestesia Regional; 2020 [cited 2020 Jun 04]; 3(49). Doi: https://doi.org/10.25237/revchilanestv49n03.08.

12. Montero Feijoo A, Maseda E, Adalia Bartolomé R, Aguilar G, González de Castro R, Gómez-HerrerasJ I, et al. Recomendaciones prácticas para el manejo perioperatorio del paciente con sospecha o infección grave por coronavirus SARS-CoV-2. Madrid: Rev esp anestesiol reanim; 2020; 67(5):253-260. DOI: 10.1016/j.redar.2020.03.003

13. Agência Nacional de Vigilância Sanitária (ANVISA). Nota Técnica GVIMS/GGTES/ANVISA № 04/2020: Orientações para serviços de saúde: Medidas de prevenção e controle que devem ser adotadas durante a assistência aos casos suspeitos ou confirmados de infecção pelo novo coronavirus (SARSCoV-2). Brasilia: ANVISA; 2020 [cited 2020 Jun 02]. Available from: http://portal.anvisa.gov.br/documents/33852/271858/ Nota+T\%C3\%A9cnica+n+04-2020+GVIMS-GGTES-ANVISA/ ab598660-3de4-4f14-8e6f-b934lc196b28. 